3 Hill PC, Jackson-Sillah DJ, Fox A, et al. Incidence of tuberculosis and the predictive value of ELISPOT and Mantoux tests in Gambian case contacts. PLoS One 2008; 3: e1379.

4 Bakir M, Millington KA, Soysal A, et al. Prognostic value of a Tcell-based, interferon-gamma biomarker in children with tuberculosis contact. Ann Intern Med 2008; 149: 777-787.

5 Diel R, Loddenkemper R, Niemann S, et al. Negative and positive predictive value of a whole-blood interferon- $\gamma$ release assay for developing active tuberculosis: an update. Am J Respir Crit Care Med 2011; 183: 88-95.

6 Kik SV, Franken WP, Mensen M, et al. Predictive value for progression to tuberculosis by IGRAs and TST in immigrant contacts. Eur Respir J 2010; 35: 1346-1353.

7 Leung CC, Yam WC, Yew WW, et al. T-Spot.TB outperforms tuberculin skin test in predicting tuberculosis disease. Am J Respir Crit Care Med 2010; 182: 834-884.
8 Aichelburg MC, Rieger A, Breitenecker F, et al. Detection and prediction of active tuberculosis disease by a whole-blood interferon- $\gamma$ release assay in HIV-1-infected individuals. Clin Infect Dis 2009; 48: 954-962.

9 Clark SA, Martin SL, Pozniak A, et al. Tuberculosis antigenspecific immune responses can be detected using enzyme-linked immunospot technology in human immunodeficiency virus (HIV)-1 patients with advanced disease. Clin Exp Immunol 2007; 150: 238-244.

10 Pareek M, Watson JP, Ormerod LP, et al. Screening of immigrants in the UK for imported latent tuberculosis: a multicentre cohort study and cost-effectiveness analysis. Lancet Infect Dis 2011; 11: 435-444.

\title{
Increase in walk distance is not enough evidence to add a walk to the 6-minute walk test
}

\section{To the Editors:}

We read with interest the work of HeRnANDES et al. [1]. The authors performed a cross-sectional analysis using data from 1,514 patients with moderate-to-very severe chronic obstructive pulmonary disease who performed 6-min walks on consecutive days and recommended that, because the distance of the second walk was longer than that of the first, two walks should be performed [1]. Their finding that the walk distance increases by $7 \%$ on the second walk (27-m increase from a baseline of $391 \mathrm{~m}$ ) validates our previous findings and adds new knowledge about the variables that predict improvement in walk distance [2]. These predictors of improvement may be helpful in identifying which subgroups of patients may benefit the most from performing two walks instead of one per 6-min walk test.

However, documenting an increase in walk distance is not enough evidence to add an additional walk to the 6-min walk test. To determine whether an additional walk should be performed, the authors should investigate whether adding a second walk makes the test more accurate, i.e. allows better correlation of changes in walk distance with a gold-standard measurement of exercise capacity, such as a cardiopulmonary exercise testing, or a better representation of change in patientreported activity limitation measured by symptom-based questionnaires [3]. Also, it should be determined which walk distance leads to more precise test results over longitudinal follow-up, i.e. has less random error reflected by a smaller standard deviation. Less random error would lead to reduced sample size requirements for clinical trials that use improvement in walk distance as the end-point, which will make these studies much more feasible. If the second walk were to appear superior in these analyses, the magnitude of the benefit would have to be weighed against the added cost and effort required for a second walk. Unfortunately, the authors do not include a gold-standard measurement of exercise capacity, patient-reported exercise limitation, longitudinal follow-up or data on relative magnitude of benefit, and therefore, do not provide enough evidence to support their recommendation to add a second walk.

Even if an additional walk were to be performed, should we be using the second walk distance as the formal result of the test in all our patients, as implied by the authors [1]? 18\% of their patients walked a shorter distance on the second walk. This could have occurred for a number of reasons, such as residual fatigue from the first walk or a lack of motivation to repeat the walk distance. In such cases, this shorter second walk distance may not best represent true exercise capacity; rather, the best of two, or even an average of two, walk distances may be a better alternative. However, HeRNANDES et al. [1] did not determine the optimal interpretation of the two walk distances.

To support their recommendation for using the second walk distance, the authors make indirect arguments in their discussion based on a Bland-Altman analysis that compared the first walk distance to the second. However, the BlandAltman analysis is a test of agreement, and cannot be used to determine which measurement is better [4].

Therefore, noticing an increase in the 6-min walk distance and identifying factors that predict the increase is a useful addition to our understanding of the 6-min walk test, but does not provide enough evidence to recommend an additional walk be performed. Unless such evidence becomes available, the benefit of a second 6-min walk remains speculative [5].

\section{H.S. Kulkarni*, D. Chandra" ${ }^{\#}$ and F.C. Sciurba ${ }^{\#}$}

*Dept of Medicine, University of Pittsburgh Medical Center, and "Emphysema Research Center, Division of Pulmonary and Critical Care Medicine, University of Pittsburgh, Pittsburgh, PA, USA. 
Correspondence: F.C. Sciurba, Emphysema Research Center, Division of Pulmonary and Critical Care Medicine, University of Pittsburgh, Kaufmann Building, Suite 1211, 3471 Fifth Avenue, Pittsburgh, PA 15213, USA. E-mail: sciurbafc@upmc.edu

Statement of Interest: None declared.

\section{REFERENCES}

1 Hernandes NA, Wouters EF, Meijer K, et al. Reproducibility of 6minute walking test in patients with COPD. Eur Respir J 2010; 38: 261-267.

2 Sciurba F, Criner GJ, Lee SM, et al. Six-minute walk distance in chronic obstructive pulmonary disease: reproducibility and effect of walking course layout and length. Am J Respir Crit Care Med 2003; 167: 1522-1527.

3 Oga T, Nishimura K, Tsukino M, et al. Analysis of the factors related to mortality in chronic obstructive pulmonary disease: role of exercise capacity and health status. Am J Respir Crit Care Med 2003; 167: 544-549.

4 Hanneman SK. Design, analysis, and interpretation of methodcomparison studies. AACN Adv Crit Care 2008; 19: 223-234.

5 ATS Committee on Proficiency Standards for Clinical Pulmonary Function Laboratories. ATS statement: guidelines for the six-minute walk test. Am J Respir Crit Care Med 2002; 166: 111-117.

\section{DOI: $10.1183 / 09031936.00113211$}

\section{From the authors:}

H.S. Kulkarni and coworkers argue that a mean increase in 6min walk distance (6MWD) of $27 \mathrm{~m}$ during a second 6-min walk test $(6 \mathrm{MWT})$ in 1,514 patients with chronic obstructive pulmonary disease (COPD) still does not provide enough evidence to consider performing two 6MWTs [1]. Even though we very much appreciate this correspondence, we disagree with the arguments and conclusions of H.S. Kulkarni and coworkers.

H.S. Kulkarni and coworkers state that we implied that only the result of the second 6MWT should be used. This is incorrect; we did not state this in our manuscript [1]. Indeed, $18 \%$ of the patients with COPD walked further during the first $6 \mathrm{MWT}$. Moreover, the use of the best of two 6MWTs (defined as the best $6 \mathrm{MWD}$ ) is very common in the COPD literature [2-5].

$82 \%$ of our patients with COPD walked further during the second $6 \mathrm{MWT}$. Indeed, the mean difference between the first and second 6MWT of $27 \mathrm{~min}$ is currently considered as clinically important in patients with moderate-to-very-severe COPD $[6,7]$. Moreover, we verified, through the Bland-Altman analysis, that the limits of agreement between the first and second 6MWT largely exceed the upper limit of clinically important change [8]. Both findings support the implementation of a second 6MWT. Moreover, an improvement in $6 \mathrm{MWD}$ as a result of learning may be interpreted erroneously as a positive treatment; and the yearly change in 6MWD in COPD is estimated to be, on average, $-26 \mathrm{~m}$ [9]. These are two additional strong arguments in favour of considering a second 6MWT.

H.S. Kulkarni and coworkers argue that the 6MWT should be compared with the outcomes of a cardiopulmonary cycling test, health status or symptoms. Nevertheless, the proposed outcomes may not be valid anchors for anchor-based minimal important difference estimates [10-12]. The argument of H.S. Kulkarni and coworkers that a second 6MWT is too expensive and requires too much effort seems invalid, as a $6 \mathrm{MWT}$ is simple and less time consuming than a formal cardiopulmonary exercise test. Moreover, we believe that the benefits of avoiding measurement error when assessing functional exercise capacity and prognosis in COPD are more relevant than the modest costs and effort required to perform a second $6 \mathrm{MWT}$. In addition, reimbursement is arranged [13].

In conclusion, the $6 \mathrm{MWT}$ is a simple, easy and cheap test, with valuable clinical information, ignoring the fact $82 \%$ of the patients walk further during the second $6 \mathrm{MWT}$ can have clinical consequences, as discussed extensively in our article [1].

\section{N.A. Hernandes ${ }^{*, \#, \Phi}$, E.F.M. Wouters ${ }^{*,+}$, K. Meijer ${ }^{\S}$, J. Annegarn ${ }^{\S}$, F. Pitta ${ }^{\#}$ and M.A. Spruit*}

*Programme Development Centre, CIRO Centre of Expertise for Chronic Organ Failure, Horn, ${ }^{+}$Dept of Respiratory Medicine, Maastricht University Medical Centre, ${ }^{\S}$ Dept of Human Movement Science, Faculty of Health, Medicine and Life Sciences, Maastricht University, Maastricht, The Netherlands. "Laboratory of Research in Respiratory Physiotherapy, Dept of Physiotherapy, Universidade Estadual de Londrina, and "Universidade Norte do Paraná, Londrina, Brazil.

Correspondence: N.A. Hernandes, Universidade Norte do Paraná, Rua Montese, 149 apt. 502, Jd. Higienópolis, CEP, 86015-020, Londrina, Paraná, Brazil. E-mail: nyhernandes@ gmail.com

Statement of Interest: None declared.

\section{REFERENCES}

1 Hernandes NA, Wouters EF, Meijer K, et al. Reproducibility of 6minute walking test in patients with COPD. Eur Respir J 2011; 38: 261-267.

2 Spruit MA, Wouters EF. New modalities of pulmonary rehabilitation in patients with chronic obstructive pulmonary disease. Sports Med 2007; 37: 501-518.

3 Spruit MA, Gosselink R, Troosters T, et al. Resistance versus endurance training in patients with $\mathrm{COPD}$ and peripheral muscle weakness. Eur Respir J 2002; 19: 1072-1078.

4 Pitta F, Troosters T, Probst VS, et al. Are patients with COPD more active after pulmonary rehabilitation? Chest 2008; 134: 273-280.

5 Butland RJ, Pang J, Gross ER, et al. Two-, six-, and 12-minute walking tests in respiratory disease. Br Med J (Clin Res Ed) 1982; 284: 1607-1608.

6 Puhan MA, Chandra D, Mosenifar Z, et al. The minimal important difference of exercise tests in severe COPD. Eur Respir J 2011; 37: 784-790.

7 Holland AE, Hill CJ, Rasekaba T, et al. Updating the minimal important difference for six-minute walk distance in patients with chronic obstructive pulmonary disease. Arch Phys Med Rehabil 2010; 91: 221-225.

8 Puhan MA, Mador MJ, Held U, et al. Interpretation of treatment changes in 6-minute walk distance in patients with COPD. Eur Respir J 2008; 32: 637-643.

9 Pinto-Plata VM, Cote C, Cabral H, et al. The 6-min walk distance: change over time and value as a predictor of survival in severe COPD. Eur Respir J 2004; 23: 28-33. 